ISSN 2525-4812 (versão online)

ISSN 2238-7641 (versão impressa)

http://www.revistaterceiramargem.com/

index.php/terceiramargem/index
Recebido em: 31/5/2020

Aprovado para Sober 2020: 23/7/2020

Aceito para RTMA: 28/4/2021

Período de publicação: jan./jul. 2021
Revista Terceira Margem Amazônia

(v. $7 \cdot$ n. $17 \cdot$ Jan./Jun. 2021)

Como citar o artigo:

MAFRA, R. Z.; SANTOS, A. B.; SOUSA, L. V. de C.; BRASIL, M. C.; FERREIRA, M. C. Crédito rural para a inovação da agropecuária do estado do Amazonas no período de 2002 a 2018. Revista Terceira Margem Amazônia, v. 7, n. 17, p. 73-91, 2021.DOI: http://dx.doi.org/10.36882/2525-4812.2021v7i17.p73-91

\title{
CRÉDITO RURAL PARA A INOVAÇÃO DA AGROPECUÁRIA DO ESTADO DO AMAZONAS NO PERÍODO DE 2002 A 2018
}

\author{
Rosana Zau Mafra \\ Andreia Brasil Santos ${ }^{2}$ \\ Lucas Vitor de Carvalho Sousa ${ }^{3}$ \\ Marilia Carvalho Brasil ${ }^{4}$ \\ Márcio Antônio Couto Ferreira
}

Resumo: A considerar que a inovação é o caminho para que ocorra o desenvolvimento econômico de uma nação e que o crédito rural é um instrumento para impulsionar a produção local, contemplando em suas linhas a aquisição de máquinas e equipamentos - uma das modalidades de inovação, este estudo tem como objetivo identificar a dinâmica do crédito rural para a inovação do setor primário no estado do Amazonas. Trata-se de uma pesquisa comparativa e quantitativa para a qual se utilizou a base de dados do Banco Central do Brasil (Bacen) - Matriz Quantidade e Valor dos Contratos de Investimento por Município. Adotou-se o Índice Normalizado de Crédito Rural (INCR) de Toledo Neto e Couto Junior (2011), o qual permitiu caracterizar a especialização da conta Investimento (se agrícola ou pecuária). O resultado aponta para uma expansão expressiva de recursos destinados à atividade agrícola no período de 2002 a 2018 , sendo intensificada após o período da crise de 2008, além de uma mudança no padrão de especialização do crédito rural do estado do Amazonas, indo de medianamente especialista em crédito agrícola para espe-

\footnotetext{
Economista, doutora no Programa Multi-Institucional de Pós-Graduação em Biotecnologia, professora da Universidade Federal do Amazonas (Ufam), Manaus, AM.

E-mail: rosanazau@ufam.edu.br

(iD) $h t t p: / / o r c i d . o r g / 0000-0002-7133-9824$

2 Economista, doutora em Engenharia de Produção, professora da Universidade Federal do Amazonas (Ufam), Manaus, AM. E-mail: brasiland@ufam.edu.br

(D) https://orcid.org/0000-0002-6691-744X

3 Economista, doutor em Economia, professor da Universidade Federal do Amazonas (Ufam), Manaus, AM.

E-mail: lucassousa@ufam.edu.br

(D) http://orcid.org/0000-0001-7273-9312

4 Economista, mestre em Economia, professora da Universidade Federal do Amazonas (Ufam), Manaus, AM.

E-mail: mariliacbrasil@ufam.edu.br

(D) http://orcid.org/0000-0003-4064-5092

5 Estatístico, doutor em Ciências do Ambiente e Sustentabilidade na Amazônia, professor da Universidade Federal do Amazonas (Ufam), Manaus, AM.

E-mail: marciocout@yahoo.com.br

(D) http://orcid.org/0000-0002-5925-9928
} 
cialista em crédito pecuário. Junto a isso observou-se um aumento na aquisição de máquinas, equipamentos, materiais e utensílios agrícolas, bem como a atividade de melhoramento das explorações agrícolas e pecuárias, caracterizando atividades inovativas nos dois setores. O resultado do estudo contribui para a divulgação da aplicação do crédito rural no estado do Amazonas, em especial para inovação de processo.

Palavras-chave: crédito rural, investimento, inovação, estado do Amazonas, INCR.

\title{
RURAL CREDIT FOR INNOVATION IN AGRICULTURE AND LIVESTOCK IN THE STATE OF AMAZONAS DURING THE PERIOD 2002 TO 2018
}

\begin{abstract}
Considering that innovation is the path to the economic development of a nation, and that rural credit represents an instrument to boost local production, and that includes, in its arrangements, machinery and equipment acquisition - one of innovation type, this study aims to identify the dynamics of rural credit to innovation in agriculture and livestock of the State of Amazonas. This is a comparative and quantitative research for which was used Brazilian Central Bank (Bacen) database - Quantity and value of the Contracts of investment per municipality. The Normalized Rural Credit Index (INCR) of Toledo Neto and Couto Junior (2011) which made it possible to characterize the specialization of the Investment account (whether agricultural or livestock). The result points to a significant expansion of resources destined to agricultural activity, in the period 2002-2018, being intensified after the period of the economic crisis of 2008, in addition to a change in the pattern of specialization of rural credit in the state of Amazonas, going from 'medium to specialist in agricultural credit' to 'livestock credit specialist'. Along with this, an increase in the acquisition of agricultural machinery, equipment, materials and utensils was observed, as well as the improvement of agricultural and livestock farms, characterizing innovative activities in both sector. The result of the study contributes to the dissemination of the application of rural credit resources in the state of Amazonas, especially for process innovation.
\end{abstract}

Keywords: ural credit, investment, innovation, state of Amazonas, INCR.

\section{Introdução}

Inúmeros são os autores que enxergavam na inovação um papel de ruptura entre o antigo e o novo, reestruturando a sociedade em todos os seus aspectos, criando novos laços, novas interações e novas necessidades. Para Schumpeter (1984), a inovação não apenas necessitava de uma materialização da ideia, mas ser comercializada para que tal invento recebesse essa denominação. Porter (1981) corrobora esse pensamento, indicando que inovação é um novo meio de se fazer, desde que ocorra a comercialização. As inovações representam uma possibilidade de um novo cenário de desenvolvimento da sociedade, colocando em destaque mudanças sociais que até então eram determinadas por indefinições, levantando um conjunto de questões que não possui respostas conclusivas (PINHO, 2008).

Em um estudo da Organização para Cooperação e Desenvolvimento Econômico (OCDE) verificou-se, por técnicas econométricas, alto grau de correlação entre a renda per capita e o quantitativo de trabalhadores de ciência, tecnologia e engenharia em relação ao total da população empregada (SALERNO, 2017). O autor acrescenta que a União Europeia possui o programa Clean Sky para o desenvolvimento de tecnologias em aviões para redução de ruídos e poluentes; que os Estados Unidos ofertam programas de apoio ao desenvolvimento tecnológico e à manufatura; assim como a Alemanha, que desenvolve programas de manufatura integrada. Observa-se que 
esses países, além de investirem fortemente em inovação, possuem alta renda per capita, enquanto o Brasil tenta acompanhar o ritmo por meio da Lei do Bem (BRASIL, 2005) e do Programa Nacional de Plataformas do Conhecimento (BRASIL, 2014), entre algumas iniciativas que visam estimular a inovação no País e, por conseguinte, o incremento da renda per capita.

No âmbito das unidades federativas brasileiras, o estado do Amazonas, na região Norte, foi pioneiro na implementação da Lei de Inovação Estadual, a Lei nº 3.095 de 2006 (AMAZONAS, 2006), e, no período de 2003 a 2008, a maior parte das patentes depositadas ( 85 depósitos) pelo Amazonas no Instituto Nacional da Propriedade Industrial (INPI) foram originárias das indústrias de eletroeletrônicos do Polo Industrial de Manaus (PIM), pelas empresas Nokia, Philips, Semp Toshiba, Panasonic, Sony, LG, Gradiente, Sharp, CCE, Grupo Itautec, Philco e PST (FRICKMANN; VASCONCELLOS, 2011).

Entretanto, diferentemente do que ocorre no Sul do País, em que as grandes empresas multinacionais do segmento de agroquímicos, fertilizantes e/ou sementes promovem o crescimento da atividade agropecuária e, ao contrário do industrial, no setor primário é onde o estado do Amazonas encontra os maiores desafios para inovar, conforme apontam Petry et al. (2019). Segundo os autores, as comunidades são distantes da sede do município e a maioria desconhece trabalhos que visam fomentar a inovação e a difusão na agricultura. Quando recebem do governo, por exemplo, sementes de milho híbrido, ferramentas agrícolas (facão, enxada, foice) e motores para os barcos, associam as iniciativas a campanhas eleitorais, que, por sua vez, não oferecem acompanhamento no campo e por isso não se configura em difusão de inovações de tecnologias na agricultura (PETRY et al., 2019).

Recentemente, o governo federal lançou o Projeto Inovação nas Cadeias Produtivas da Agropecuária para a Conservação Florestal na Amazônia Legal (BRASIL, 2019). O objetivo desse projeto é levar inovação para as cadeias produtivas da carne, soja e madeira, e será implantado entre 2020 e 2024 nos seguintes estados: Amazonas, Mato Grosso, Pará, Rondônia e Tocantins. Ocorre que nenhuma dessas atividades primárias são predominantes no estado do Amazonas. Durante os anos de 2015 e 2017, na cultura temporária, abacaxi, cana-de-açúcar e mandioca foram os maiores alimentos produzidos, tanto na área colhida quanto na área produzida no estado, enquanto na cultura permanente o destaque foi para banana, laranja e guaraná (AMAZONAS, 2017). Quanto à pecuária, tem destaque no efetivo de rebanhos o bovino, que no triênio 20152017 somava cerca de 3.952.720 cabeças de gado; o restante é composto por bubalinos, equinos, caprinos, suínos, etc. (AMAZONAS, 2017).

O subsídio, entretanto, é fundamental para a modernização, o crescimento e aprimoramento da atividade agropecuária, via utilização das novas tecnologias e o crédito rural (SEIDLER; FRITZ FILHO, 2016). Para os autores, o acesso a políticas públicas, como, por exemplo, políticas de crédito, auxilia os produtores rurais, que por sua vez investem em inovação no sistema produtivo e viabilizam melhoramento da qualidade dos produtos, o aumento da produtividade, a manutenção no mercado, o aumento da renda familiar, o aumento do valor da propriedade agrícola e o melhoramento da qualidade de vida ao desempenhar as tarefas, seja na agricultura, seja na pecuária. 
A considerar que a inovação é o caminho para que ocorra o desenvolvimento econômico de uma nação, que o crédito rural representa um instrumento para impulsionar a produção local e que o estado do Amazonas enfrenta desafios para inovar no setor primário, questiona-se: como tem sido, no estado do Amazonas, a distribuição do crédito rural para a finalidade investimento? O estudo justifica-se pela limitação de estudos relacionados ao crédito rural e à inovação no setor primário no estado do Amazonas, particularmente quanto à aplicação dos recursos do crédito rural para finalidades específicas. Além disso, aponta quais municípios amazonenses vêm sendo mais beneficiados com crédito rural para aquisição de máquinas e equipamentos e para melhoramento de explorações nos setores agrícola e pecuário.

\section{Inovação e setor agropecuário}

Schumpeter (1984) postulava maior importância ao fornecimento de crédito para o financiamento dos meios de inovação, resultando na ideia de "destruição criativa", em que a elevação do fornecimento de crédito, em um cenário de pleno emprego, ocasionaria aumento nos fatores produtivos, realocando a um novo conjunto de equilíbrio, diferente dos autores clássicos que evidenciavam a importância da poupança para os processos inovativos, visto que o foco deveria ser para o papel de descontinuidade que a inovação introduziria no sistema (PIVOTO et al., 2016). Com as contribuições de David Ricardo, evidenciou-se o monopólio temporário e a poupança de mão de obra no pioneirismo de uma nova tecnologia; Karl Marx, por sua vez, demonstrou os ganhos elevados advindos de inovações radicais, explicando a origem da riqueza pela mais-valia (SEIDLER; FRITZ FILHO, 2016).

Segundo a OCDE, a inovação compreende implementar um produto, bem ou serviço - seja ele novo ou significativamente melhorado - ou um processo, ou um novo método de marketing, ou um novo método organizacional nas práticas de negócios, na organização do local de trabalho ou nas relações externas (OECD/EUROSTAT, 2018). Em seu Manual do Oslo, a OCDE acrescenta que é necessário distinguir os diferentes tipos de inovação, que, em alguns casos, podem assumir mais de uma característica. A inovação de produto caracteriza-se pela presença de aspectos novos ou melhorados dos serviços; caso ocorra o desempenho das atividades com técnicas, equipamentos e habilidades melhoradas, há inovação por processo, podendo ocorrer inovação tanto de produto quanto de processo simultaneamente (OECD/EUROSTAT, 2018), para citar alguns tipos de inovação.

Segundo Petry et al. (2019), na agricultura, a literatura sobre inovações é diversa e desenvolveu seu próprio vocabulário. Os autores citam duas correntes: uma que investiga a geração de inovações e outra que aborda a promoção da adoção e o uso de inovações no agronegócio (a difusão). Essa última faz distinção entre as inovações que são incorporadas em bens ou produtos, tais como tratores; fertilizantes, sementes e insumos diversos, quando se tratar de agricultura; ou combinações de forragens, por exemplo, quando se tratar de pecuária.

A inovação na agricultura, de acordo com Van Der Veen (2010), está relacionada com o aumento da produção de alimentos, a melhoria da qualidade de produtos, as condições de cultivo e processos de produção. Como exemplo tem-se a adoção de novas variedades de sementes, novas práticas de cultivo, etc. A inovação na pecuária se reflete nas práticas modernas de produção de 
carne bovina, como, por exemplo, realização de cruzamento de raças para melhoramento genético e de reprodução, pastejo rotacionado, seguido por práticas de gestão agrícola alternativas, como gestão holística e pecuária orgânica, dieta do animal, utilização de ionóforos e outros compostos e uso das biotecnologias, entre tantas outras (FERNANDES et al., 2017).

Segundo Boza et al. (2017), ao longo das décadas, houve uma mudança na configuração da agropecuária brasileira, principalmente decorrente das alterações na composição da produção, necessitando de forças mecânicas e novas tecnologias para os trabalhos agrários, aumentando a utilização de insumos mais modernos e implementos agrícolas. Segundo os autores, a inovação contribuiu para a produção do agronegócio brasileiro, que cresceu exponencialmente nas últimas décadas - em 1975 a colheita de grãos era de 45 milhões de toneladas, expandindo para 58 milhões em 1990, e na safra 2013/2014 atingiu 192,8 milhões de toneladas.

Entretanto, o acesso à tecnologia pela agropecuária brasileira, a difusão dos novos conhecimentos e técnicas dão-se de forma assimétrica entre regiões, produtores e até sistemas (BOZA et al., 2017). Ou seja, o crescimento do agronegócio está relacionado à inovação em contextos de culturas expressivas (soja, milho, trigo entre outras) dos "cinturões verdes" do País. No caso do estado do Amazonas, a produtividade agrícola é baixa, pois emprega conhecimentos tradicionais e rudimentares, e poucos esforços foram direcionados para a compreensão da inovação e difusão agrícolas (PETRY et al., 2019).

\section{Crédito rural: panorama e programas para a inovação}

O crédito rural nacional teve início em 1965, com sua institucionalização por meio da Lei $\mathrm{n}^{\circ} 4.829$, de 5 de novembro de 1965, que em seu art. $2^{\circ}$ classifica-o como "suprimento de recursos financeiros por entidades públicas e estabelecimentos de crédito particulares a produtores rurais ou a suas cooperativas para aplicação exclusiva em atividades que se enquadrem nos objetivos indicados na legislação em vigor" (BRASIL, 1965). Crédito este que possui como objetivos específicos, de acordo com a citada lei:

I - estimular o incremento ordenado dos investimentos rurais, inclusive para armazenamento, beneficiamento e industrialização dos produtos agropecuários, quando efetuado por cooperativas ou pelo produtor na sua propriedade rural; II - favorecer o custeio oportuno e adequado da produção e a comercialização de produtos agropecuários; III possibilitar o fortalecimento econômico dos produtores rurais, notadamente pequenos e médios; IV - incentivar a introdução de métodos racionais de produção, visando ao aumento da produtividade e à melhoria do padrão de vida das populações rurais, e à adequada defesa do solo (BRASIL, 1965).

Entre 1999 e 2013, o crédito rural no Brasil foi utilizado principalmente para custeio e comercialização. O uso para custeio envolve custos relacionados à produção, como preparação e limpeza da área ou terreno, plantio e colheita, entre outras atividades, além de insumos agrícolas. O uso para comercialização ajuda na promoção dos produtos (LOPES et al., 2016). O uso para investimento destina-se à aquisição de bens ou serviços fixos ou semifixos (BACEN, 2018). 
De acordo com Fürstenau (1988), a utilização de recursos cujo destino é o investimento tem sua importância na aplicação como instrumento pela introdução ou ampliação, alterando positivamente a produtividade do trabalho e da terra, de técnicas mais produtivas. A destinação de subsídios encaminhados à agricultura possui papel fundamental para modernização, crescimento e aprimoramento da atividade via utilização das novas tecnologias (SEIDLER; FRITZ FILHO, 2016).

De acordo com Lopes et al. (2016), na última década, o agronegócio brasileiro correspondeu a $22 \%$ e $25 \%$ do Produto Interno Bruto (PIB). A Figura 1 ilustra o total de dispêndio dos financiamentos disponibilizados, apresentando predominância de crédito destinado a custeio, especialmente a partir de 2007.

Figura 1. Quantidade de contratos e volume de recursos a preços correntes de dezembro de 2017 aplicados pelo Sistema Nacional de Crédito Rural (SNCR) por finalidade - Brasil (1999-2017).

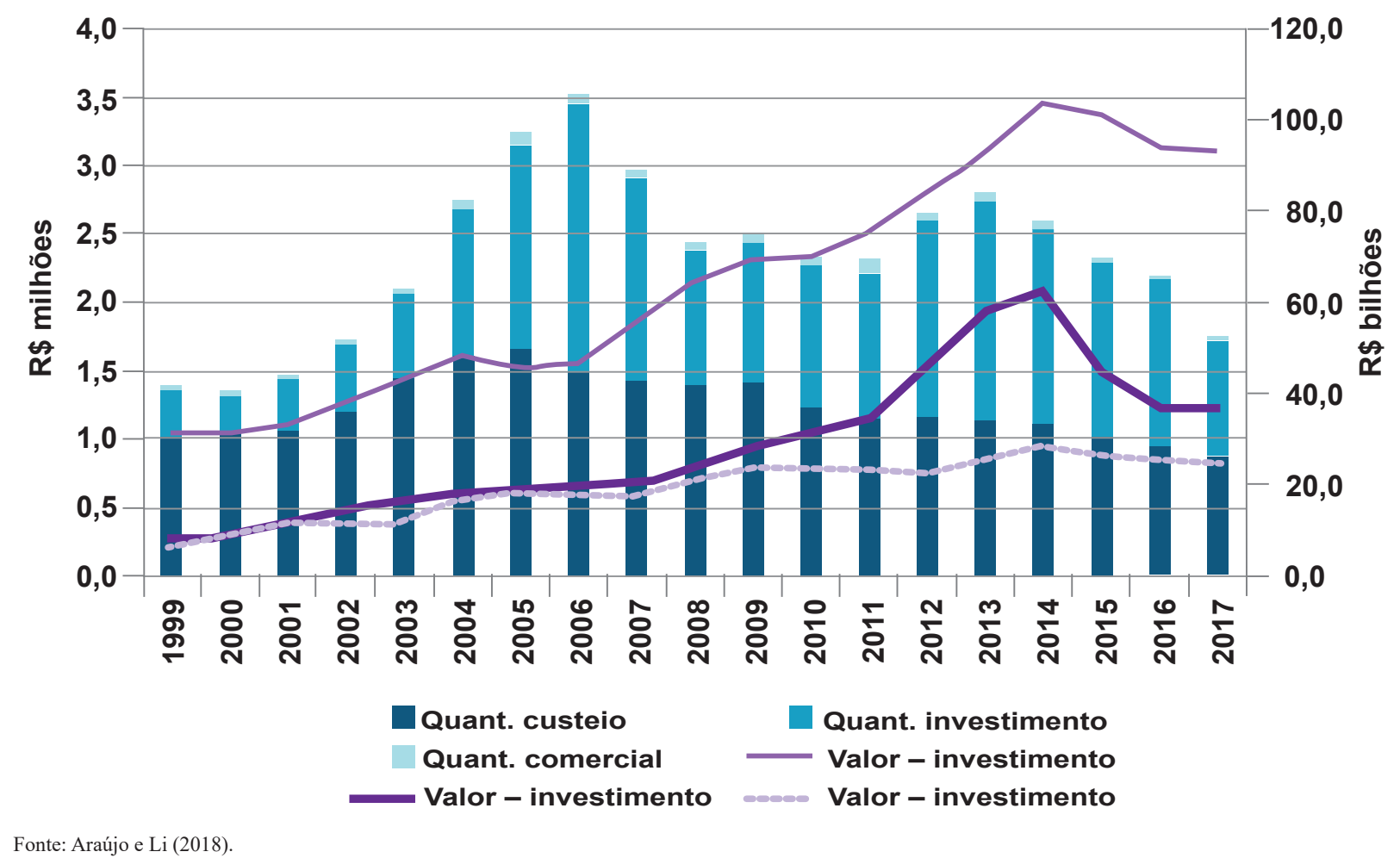

Após um retrocesso na disponibilização do crédito durante a década de 1990, houve um crescimento significativo a partir de 2003; e, em 2008, como medida adotada em resposta à crise mundial, a expansão foi intensificada, principalmente o crédito livre com taxas referenciais (MORA, 2015). No início dos anos 2000, os créditos destinados aos investimentos apresentaram uma intensificação, fruto da implementação de programas do Banco Nacional de Desenvolvimento Social (BNDES) (ARAUJO; LI, 2018). O período compreendido entre 2000 e 2010 foi marcado pela criação e reestruturação de programas destinados ao setor primário, conforme resumido na Tabela 1. 
Tabela 1. Programas de créditos rurais destinados ao desenvolvimento do setor primário brasileiro.

\begin{tabular}{|c|c|c|}
\hline Programa & Ano de criação & Finalidade \\
\hline $\begin{array}{l}\text { Programa de Modernização da } \\
\text { Agricultura e Conservação dos } \\
\text { Recursos Naturais (Moderagro) }\end{array}$ & 1999 & $\begin{array}{l}\text { Modernização e expansão da } \\
\text { produtividade, além de recuperação do } \\
\text { solo e defesa animal. }\end{array}$ \\
\hline $\begin{array}{l}\text { Programa de Modernização } \\
\text { da Frota de Tratores Agrícolas } \\
\text { e Implementos Associados e } \\
\text { Colheitadeiras (Moderfrota) }\end{array}$ & 2000 & $\begin{array}{l}\text { Financiamento para aquisição de } \\
\text { tratores, colheitadeiras, plataformas } \\
\text { de corte, pulverizadores, plantadeiras, } \\
\text { semeadoras e equipamentos para } \\
\text { beneficiamento de café. Contempla itens } \\
\text { novos e usados. }\end{array}$ \\
\hline $\begin{array}{l}\text { Programa de Incentivo à Irrigação e } \\
\text { à Produção em Ambiente Protegido } \\
\text { (Moderinfra) }\end{array}$ & 2001 & $\begin{array}{l}\text { Financiamento para o desenvolvimento } \\
\text { da agropecuária irrigada sustentável, } \\
\text { bem como para o incentivo à utilização } \\
\text { de estruturas de produção em ambiente } \\
\text { protegido e para a proteção da } \\
\text { fruticultura em climas temperados contra } \\
\text { a incidência de granizo. }\end{array}$ \\
\hline $\begin{array}{l}\text { Programa de Incentivo à } \\
\text { Construção e Modernização de } \\
\text { Unidades Armazenadoras em } \\
\text { Propriedades Rurais (Proazem) }\end{array}$ & 2002 & $\begin{array}{l}\text { Aumento da capacidade instalada de } \\
\text { armazenagem em nível de propriedades } \\
\text { rurais e modernização de unidades } \\
\text { armazenadoras atualmente existentes. }\end{array}$ \\
\hline $\begin{array}{l}\text { Programa de Desenvolvimento } \\
\text { Sustentado da Floricultura } \\
\text { (Prodeflor) }\end{array}$ & 2002 & $\begin{array}{l}\text { Aceleração do desenvolvimento da } \\
\text { floricultura brasileira e ampliação da } \\
\text { exportação de flores. }\end{array}$ \\
\hline $\begin{array}{l}\text { Programa para Construção e } \\
\text { Ampliação de Armazéns (PCA) }\end{array}$ & 2013 & $\begin{array}{l}\text { Financiamento de alterações nos } \\
\text { armazéns, tais como modernizações e } \\
\text { reformas. }\end{array}$ \\
\hline $\begin{array}{l}\text { Programa de Incentivo à Inovação } \\
\text { Tecnológica na Produção } \\
\text { Agropecuária (Inovagro) }\end{array}$ & 2013 & $\begin{array}{l}\text { Financiamento para incorporação de } \\
\text { inovações tecnológicas nas propriedades } \\
\text { rurais, visando ao aumento da } \\
\text { produtividade e melhoria de gestão. }\end{array}$ \\
\hline
\end{tabular}

Fonte: Adaptado de BACEN (2002a, 2002b); Banco do Brasil (2020a, 2020b); BNDES (2020a, 2020b, 2020c).

Cabe destacar a existência de programas antes do ano 2000 (RAMOS; MARTHA JUNIOR, 2010). O programa que se refere à inovação é o Inovagro. De acordo com Cardoso e Bittencourt (2019, p. 4), a modalidade do Inovagro envolve:

o uso de aplicativos e sistemas informatizados, o processamento de dados, a modelagem e a simulação, a automação, o uso de sistemas inteligentes, redes de sensores climáticos e de desenvolvimento das culturas, o processamento de imagem e sua interpretação, os processos geotecnológicos, a utilização da agricultura de precisão, o uso de vants e drones, o machine learning, os sistemas embarcados, e a mineração de dados Big Data para tomada de decisões, o uso correto de fertilizantes, do uso e da correção do solo, da proteção contra as pragas, da utilização de equipamentos e máquinas mais adequados, das sementes mais produtivas e das proteções contra intempéries e uso de segurança.

Algumas questões da agricultura que dificultam a concessão de crédito para a atividade, segundo Spolador (2002), são: riscos climáticos, custos transacionais altos, volatilidade dos preços, 
informações assimétricas. Porém, a intensificação da atividade tem ocorrido de forma assimétrica, visto o aumento do crédito rural para atividade pecuária.

No estado no Amazonas, Mafra et al. (2019) apontaram variações significativas na especialização de crédito rural entre 2002 e 2012. Enquanto alguns municípios se classificaram como especialistas em crédito agrícola, também se classificaram como medianamente pecuário em 2012. Ao longo dos anos, a dinâmica do crédito rural foi passando de especializado em crédito rural para a atividade agrícola para especializado em crédito rural para a pecuária, em 2018, segundo Araújo e Mafra ${ }^{6}$ (submetido), conforme se observa na Figura 2. Os autores, porém, não discriminam a finalidade do crédito rural (se para investimento ou custeio), que é o que se propõe neste estudo.

Figura 2. Índice Normalizado de Crédito Rural (INCR) do estado do Amazonas em períodos distintos.

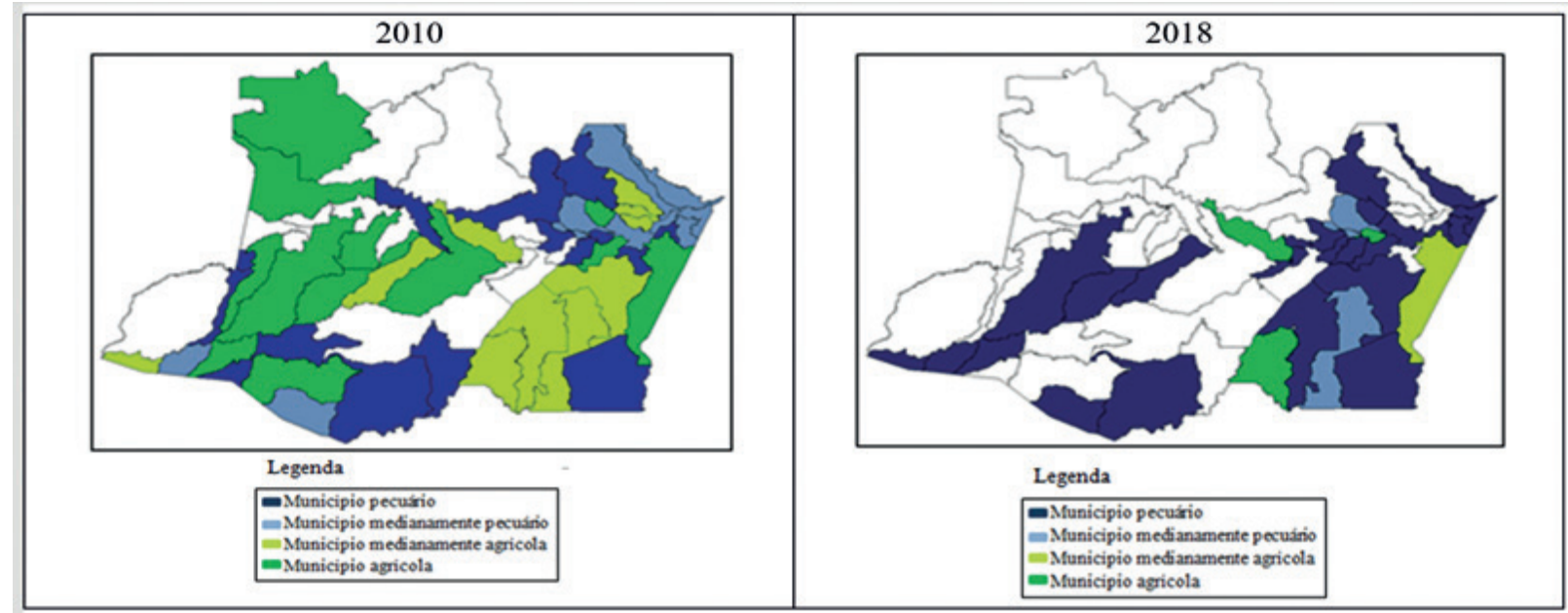

Fonte: Araújo e Mafra ${ }^{6}$ (submetido).

Smeraldi e May (2008) pontuam fatores que influenciaram a mudança no padrão de disposição do crédito rural no Amazonas ao longo da década de 2000. Segundo os autores, o baixo custo das terras amazônicas, a intensificação por uso de terras nas regiões Sul, Centro-Oeste e Sudeste para a produção de grãos e cana-de-açúcar, além da criação de tecnologias de intensificação e manejo, possibilitaram o estabelecimento da atividade pecuária na Amazônia Oriental.

Ao avaliarem a inovação e sua difusão na agricultura em áreas de várzea, no interior do estado do Amazonas, Petry et al. (2019) concluíram por um ambiente competitivo, influência da indústria de agronegócio, em que medidas como assistência técnica, medidas públicas e práticas de campo proporcionariam aumento na difusão tecnológica.

\section{Metodologia}

Trata-se de um estudo comparativo das operações de crédito rural para pecuária e para a agricultura de 62 municípios do estado do Amazonas ao longo de 17 anos fiscais. Os estudos comparativos, segundo Prodanov e Freitas (2013), centram-se em estudar semelhanças e diferenças.

${ }^{6}$ ARAÚJO, A. B. F.; MAFRA, R. Z. Distribuição espacial e concentração do crédito rural no estado do Amazonas entre 20022018. Submetido. 
Os autores comentam que o método realiza comparações com o objetivo de verificar semelhanças e explicar divergências. Os dados para a análise foram extraídos da Matriz de Dados do Crédito Rural do Bacen (Contratações - Quantidade e valor dos contratos por município), referentes aos anos de 2002 a 2018, a partir de todas as fontes de recursos e todos os programas.

Neste estudo, a inovação considerada é a de "processo", uma modalidade de inovação que consiste em melhoramentos ou criação de métodos, equipamentos e habilidades para a realização de serviços (OECD/EUROSTAT, 2018). Para isso, considerou-se a finalidade investimento, pois os recursos dessa natureza destinam-se à aquisição de bens ou serviços, cujos benefícios ocorrem nos períodos vindouros, a exemplo da aquisição de trator, obras e outras inversões fixas e semifixas relacionadas com a atividade agropecuária (BACEN, 2018). Embora alguns municípios não apresentassem valores em um ou outro período, esse fato não comprometeu o trabalho. Além da finalidade investimento, foram analisadas outras duas modalidades que poderiam auxiliar na análise da inovação no estado do Amazonas: 1) máquinas, equipamentos, materiais e utensílios; e 2) melhoramento das explorações.

Para compreender a relação existente entre os dois tipos de crédito nos municípios utilizou-se o INCR, proposto por Toledo Neto e Couto Junior (2011), expresso como segue:

$$
I N C R_{i}=\frac{C A_{i}-C P_{i}}{C A_{i}+C P_{i}}
$$

em que:

$I N C R_{i}=$ índice normalizado das aplicações de crédito rural para investimento do i-ésimo município do estado em estudo; neste caso, o Amazonas.

$C A_{i}=$ valor das operações de crédito rural para investimento aplicado na atividade agrícola no período; neste caso, de 2002 a 2018, no i-ésimo município do estado do Amazonas, em R\$.

$C P_{i}=$ valor das operações de crédito rural para investimento aplicado na atividade pecuária no período; também neste caso, de 2002 a 2018, no i-ésimo município do estado do Amazonas, em R\$.

O INCR varia entre -1 e 1, em que valores mais próximos de -1 indicam que o crédito rural para investimento destinado ao município é mais concentrado em pecuária. Caminho inverso ocorre quando o valor fica próximo de 1 , indicando que o crédito do município é concentrado na agricultura. Para facilitar o entendimento, Nascimento et al. (2011) agruparam o INCR em quatro intervalos, em que: $-1 \leq \mathrm{INCR}<-0,5$ indica que o município é especialista em crédito pecuário; $-0,5 \leq \mathrm{INCR}<0,0$ indica que o município é medianamente especialista em crédito pecuário; 0,0 $\leq \mathrm{INCR}<0,5$ indica que o município é medianamente especialista em crédito agrícola; e $0,5 \leq$ $\mathrm{INCR} \leq 1,0$ indica que o município é especialista em crédito agrícola. Municípios com valores próximos a zero demonstrariam maior integração entre agricultura e pecuária, ou seja, regiões com crédito equilibrado entre agricultura e pecuária. 


\section{Análise e discussão}

O crédito rural destinado ao estado do Amazonas entre 2002 e 2018 para a finalidade investimento totalizou R \$ 964.820.424,91, conforme ilustra a Figura 3, em que se observa predominância para atividade pecuária. $\mathrm{O}$ crescimento do crédito pecuário frente ao crédito agrícola, observado a partir de 2005, pode ser explicado por características inerentes à atividade, conforme trata Spolador (2002), tais como custos de transação altos, volatilidade dos preços dos produtos e informações assimétricas do mercado. As instituições financeiras, ao tentarem resolver esses problemas, acabaram criando contratos e acordos complexos, resultando em elevação tanto nos custos de transação quanto nos custos operacionais (EUSÉBIO; TONETO JUNIOR, 2012).

Figura 3. Crédito rural destinado ao investimento no estado do Amazonas entre 2002 e 2018.

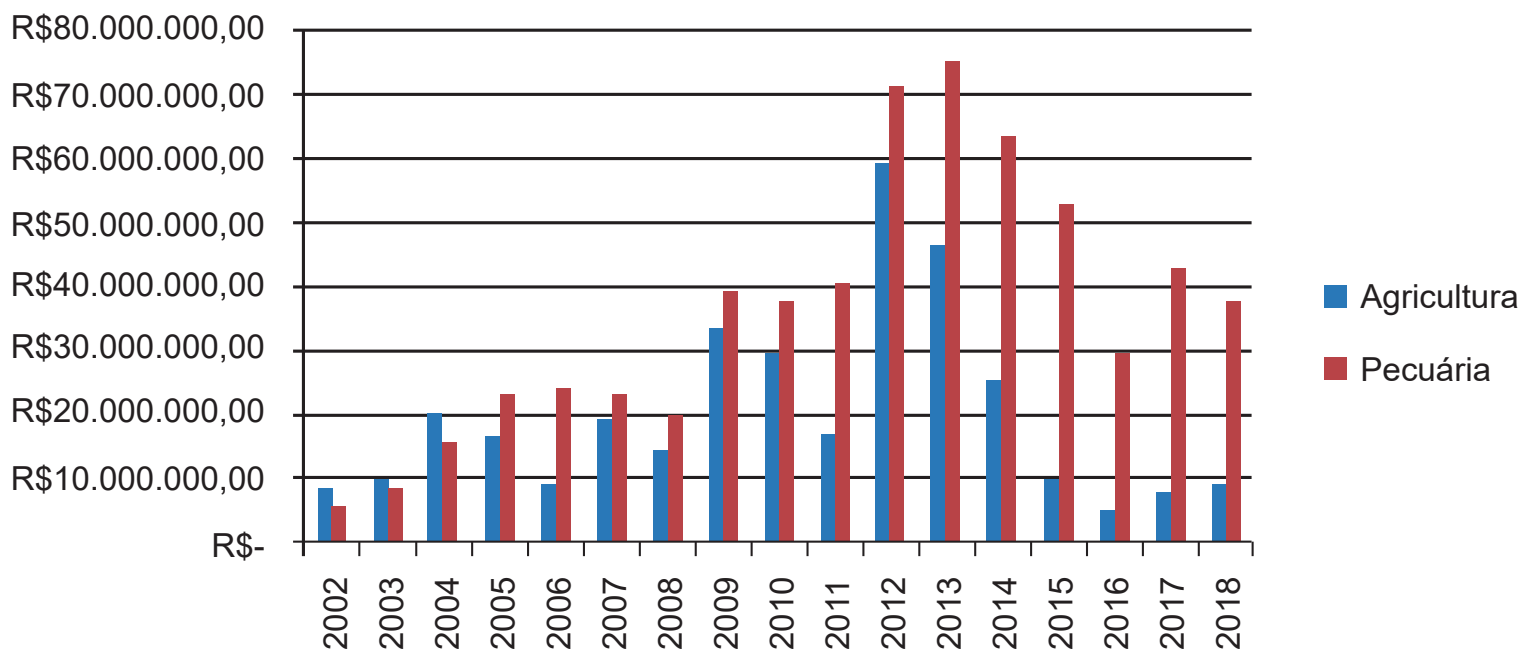

Fonte: Elaboração própria com base em BACEN (2002-2018)

Houve uma elevação dos recursos a partir de 2009 e é possível que seja reflexo da expansão do crédito em nível nacional como uma medida protetiva para os efeitos da crise de 2008, conforme explica Mora (2015). Esse montante de 2009 é quase nove vezes maior (88,79\%) que o do início da série histórica, em 2002, que foi de $\mathrm{R} \$ 14.816 .108,30$, dos quais $\mathrm{R} \$ 8.849 .874,91$ foram destinados à agricultura e $\mathrm{R} \$ 5.966 .233,39$ à pecuária. Esse cenário pode também ser reflexo da reestruturação da política agrícola do Brasil no período, resultado da dívida agrícola e dos problemas da agricultura na década anterior, citada por Gryzagoridis e Ferreira Filho (2008).

O maior quantitativo de crédito rural ocorreu em 2012, quando os recursos para a finalidade investimento somaram $\mathrm{R} \$ 132.200 .585,88$, dos quais $\mathrm{R} \$ 60.109 .076,93$ destinados à agricultura e R \$ 72.091.508,95 à pecuária. Esse comportamento segue a tendência nacional do SNCR entre 1999 e 2017, conforme expõem Araújo e Li (2018) (Figura 1).

\section{Especialização do crédito rural para investimento}

O INCR possibilitou identificar a disposição do crédito rural no estado do Amazonas para a finalidade investimento durante o período 2002-2018, tanto para atividade agrícola quanto para a pecuária. Identificou-se que, em 14 dos 17 anos fiscais estudados, o crédito rural para inves- 
timento foi direcionado para a pecuária, caracterizando o estado do Amazonas como medianamente especialista em crédito rural para investimento em pecuária (durante 10 anos) ou como especialista em crédito rural para investimento na pecuária (durante 4 anos), conforme resume a Tabela 2.

Tabela 2. Programas de créditos rurais destinados ao desenvolvimento do setor primário brasileiro.

\begin{tabular}{|c|c|c|}
\hline Ano & INCR & Classificação \\
\hline 2002 & 0,19 & Medianamente especialista em crédito agrícola \\
\hline 2003 & 0,07 & Medianamente especialista em crédito agrícola \\
\hline 2004 & 0,12 & Medianamente especialista em crédito agrícola \\
\hline 2005 & 0,17 & Medianamente especialista em crédito pecuário \\
\hline 2006 & 0,43 & Medianamente especialista em crédito pecuário \\
\hline 2007 & 0,10 & Medianamente especialista em crédito pecuário \\
\hline 2008 & 0,16 & Medianamente especialista em crédito pecuário \\
\hline 2009 & 0,08 & Medianamente especialista em crédito pecuário \\
\hline 2010 & 0,12 & Medianamente especialista em crédito pecuário \\
\hline 2011 & 0,40 & Medianamente especialista em crédito pecuário \\
\hline 2012 & 0,09 & Medianamente especialista em crédito pecuário \\
\hline 2013 & 0,24 & Medianamente especialista em crédito pecuário \\
\hline 2014 & 0,42 & Medianamente especialista em crédito pecuário \\
\hline 2015 & 0,67 & Especialista em crédito pecuário \\
\hline 2016 & 0,72 & Especialista em crédito pecuário \\
\hline 2017 & 0,68 & Especialista em crédito pecuário \\
\hline 2018 & 0,60 & Especialista em crédito pecuário \\
\hline
\end{tabular}

Fonte: Elaborado pelos autores com base em Toledo Neto e Couto Junior (2011) e Bacen (2002-2018).

Observa-se também, na Tabela 2, que somente no triênio 2002-2004 o estado do Amazonas pôde ser caracterizado como medianamente especialista em CR para investimento na agricultura. Essa dinâmica vai ao encontro de Mafra et al. (2019) e Araújo e Mafra ${ }^{7}$ (submetido), que já haviam identificado essa mudança no crédito rural ao longo dos anos sem, contudo, identificarem a finalidade do recurso (se custeio ou investimento).

A predominância de crédito rural para investimento em agropecuária, na década de 2000 , pode auxiliar na compreensão do fenômeno do desmatamento no estado do Amazonas. Rivero et al. (2009) analisaram o desmatamento na Amazônia e constataram, por meio de regressões lineares, forte correlação entre o desmatamento amazônico e a atividade pecuária, oriunda principalmente da criação bovina. Somam-se a isso as oportunidades tecnológicas apontadas por Smeraldi e May (2008) quando pontuam fatores que influenciaram a mudança no padrão de disposição do crédito rural no Amazonas ao longo da década de 2000: cercas eletrificadas sob lotação rotativa que possibilitam elevação de eficiência no uso da pastagem, formulação de suplementos minerais para o rebanho e melhoramento genético a partir da inseminação artificial.

\footnotetext{
7 ARAÚJO, A. B. F.; MAFRA, R. Z. Distribuição espacial e concentração do crédito rural no estado do Amazonas entre 20022018. Submetido.
} 


\section{Crédito rural para inovação}

Considerando que o crédito rural para a finalidade investimento não possibilita identificar em que exatamente o recurso foi aplicado, optou-se por utilizar duas modalidades adicionais de crédito rural que apontam ações voltadas para a inovação no setor primário: 1) máquinas, equipamentos, materiais e utensílios para agricultura e para a pecuária (a partir daqui será citada de forma mais reduzida: "máquinas e equipamentos para..."); e 2) melhoramento das explorações na agricultura e na pecuária. Observa-se, pela Figura 4, que os recursos destinados ao melhoramento de explorações pecuárias são expressivos na maior parte do período estudado.

Figura 4. Recursos financeiros destinados à inovação na agropecuária amazonense entre 2002 e 2018.

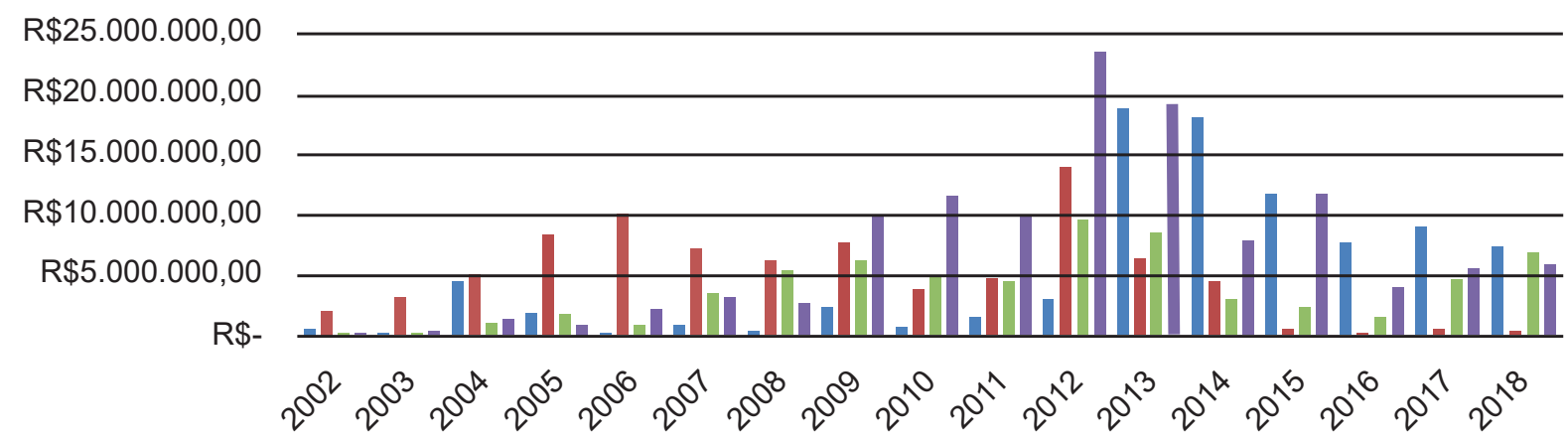

\footnotetext{
Melhoramento das explorações agrícolas

Melhoramento das explorações pecuárias

- Máquinas, equipamentos, materiais e utensílios agrícolas

Máquinas, equipamentos, materiais e utensílios pecuários
}

Fonte: Elaboração própria com base em BACEN (2002-2018).

Chama atenção, contudo, o comportamento do recurso destinado ao melhoramento das explorações agrícolas, o qual, a partir de 2013, veio ficando acima do das demais modalidades.

Ainda em 2002, o total de recursos para as duas modalidades alcançou R $\$ 2.798 .644,77$, sendo o maior volume destinado aos melhoramentos das explorações pecuárias ( $\mathrm{R}$ 2.107.311,10). A partir de 2004, os valores totais já ultrapassavam valores superiores a R \$10 milhões, alcançando um total de $\mathrm{R} \$ 12.359 .402,10$.

Em 2013, ano de maior aporte de crédito rural para ações voltadas para a inovação no campo (totalizando R \$ 19.332.292,17), os recursos foram destinados para aquisição de máquinas e equipamentos para a pecuária e para ações de melhoramento das explorações na agricultura, ou seja, finalidades adversas para ambas as atividades.

A redução desses recursos nos anos subsequentes ocorreu tanto para a atividade agrícola quanto para a pecuária, chegando a um total de $\mathrm{R} \$ 6.050 .652,10 \mathrm{em} 2018$. Ainda assim, as finalidades adversas para ambas as atividades seguem o mesmo padrão dos anos anteriores.

No período de 2013 a 2018, os municípios que mais acessaram recursos destinados a máquinas e equipamentos para agricultura e para a pecuária foram Manacapuru e Anamã, conforme se observa na Tabela 3. 
Tabela 3. Crédito para máquinas, equipamentos, materiais e utensílios para agricultura e para pecuária no estado do Amazonas entre 2013 e 2018.

\begin{tabular}{|c|c|c|c|}
\hline Município & $\begin{array}{c}\text { Agricultura - Valor dos } \\
\text { projetos }(\mathbf{R} \$)\end{array}$ & Município & $\begin{array}{c}\text { Pecuária - Valor dos } \\
\text { projetos }(\mathbf{R} \$)\end{array}$ \\
\hline Manacapuru & $2.073 .178,92$ & Anamã & 4.102 .798 \\
\hline Manaus & $1.556 .390,97$ & Boa Vista do Ramos & 3.846 .029 \\
\hline Iranduba & $1.439 .604,07$ & Boca do Acre & 2.933 .139 \\
\hline Presidente Figueiredo & $1.319 .283,81$ & Manacapuru & 2.876 .673 \\
\hline Beruri & $995.769,00$ & Parintins & 2.874 .227 \\
\hline Itacoatiara & $906.091,92$ & Manicoré & 2.438 .389 \\
\hline Rio Preto da Eva & $823.154,87$ & Manaus & 2.018 .182 \\
\hline Maués & $466.866,00$ & Autazes & 1.748 .314 \\
\hline Barreirinha & $409.980,82$ & Itacoatiara & 1.410 .609 \\
\hline Manicoré & $379.789,10$ & Guajará & 1.315 .727 \\
\hline Parintins & $301.805,31$ & Barreirinha & 1.272 .827 \\
\hline Anamã & $223.225,00$ & Apuí & 1.250 .295 \\
\hline Nhamundá & $163.695,66$ & Lábrea & 994.854 \\
\hline Boca do Acre & $157.067,28$ & Nhamundá & 955.583 \\
\hline Carauari & $91.178,80$ & Beruri & 892.742 \\
\hline Autazes & $33.697,65$ & Maués & 753.100 \\
\hline Jutaí & $15.026,55$ & Fonte Boa & 694.146 \\
\hline Codajás & $10.030,00$ & Coari & 649.334 \\
\hline Uarini & $5.215,80$ & São Paulo de Olivença & 636.099 \\
\hline Demais municípios & 0,00 & Demais municípios & 4.342 .141 \\
\hline Oculto & $12.129 .570,97$ & Oculto & 19.472 .140 \\
\hline Total & $23.500 .622,50$ & Total & 57.477 .348 \\
\hline
\end{tabular}

Fonte: Elaborado pelos autores com base em Bacen (2013-2018).

Observa-se também, na Tabela 3, que outros 11 municípios (dos 19 contemplados no período em análise) foram beneficiados com recursos para ambas as atividades: agricultura e pecuária. Cabe observar que, em 2019, dos numerosos focos de calor registrados muitos ocorreram em alguns desses municípios contemplados com essa modalidade: Apuí (623 focos), Lábrea (119), Manicoré (94), Boca do Acre (32), Maués (30), Manacapuru (18) e Autazes (10) (FUNARI, 2019), confirmando a intensificação das atividades agropecuárias e os fatores apontados por Smeraldi e May (2008).

Ainda sobre a Figura 4, observa-se que os recursos para máquinas e equipamentos para a pecuária foram maiores que para a atividade agrícola até 2012. Nos anos subsequentes, tem-se uma inversão do desempenho, destacando-se os recursos destinados a melhoramentos na agricultura. Nessa modalidade, o município que se destaca é Boca do Acre, conforme se observa na Tabela 4.

Pela Tabela 4, 21 dos 31 municípios foram beneficiados com recursos para ações de melhoramento das explorações para as duas atividades: agricultura e pecuária. Manacapuru surge como o município contemplado nas duas modalidades (máquinas e melhoramentos) e nas duas 
atividades (pecuária e agrícola). Esse município está entre os com maior PIB agropecuário no estado do Amazonas em 2016 (ARAUJO; MAFRA ${ }^{8}$, submetido).

Tabela 4. Crédito para ações de melhoramento das explorações na agricultura e para a pecuária no estado do Amazonas entre 2013 e 2018.

\begin{tabular}{|c|c|c|c|}
\hline Município & $\begin{array}{c}\text { Agricultura - Valor dos } \\
\text { projetos (R\$) }\end{array}$ & Município & $\begin{array}{c}\text { Pecuária - Valor dos } \\
\text { projetos (R\$) }\end{array}$ \\
\hline Boca do Acre & $12.644 .267,68$ & Parintins & $2.064 .463,14$ \\
\hline Autazes & $4.276 .926,52$ & Iranduba & $1.436 .512,46$ \\
\hline Manaus & $3.958 .341,10$ & Barreirinha & $1.263 .230,33$ \\
\hline Itacoatiara & $3.582 .443,49$ & Rio Preto da Eva & $1.175 .452,71$ \\
\hline Lábrea & $2.324 .227,27$ & Boca do Acre & $610.580,03$ \\
\hline Iranduba & $1.395 .866,61$ & Manacapuru & $508.564,44$ \\
\hline Manacapuru & $1.384 .943,90$ & Careiro & $423.652,03$ \\
\hline Manicoré & $1.140 .162,20$ & Borba & $391.200,00$ \\
\hline Boa Vista do Ramos & $1.113 .105,28$ & Anamã & $381.310,56$ \\
\hline Parintins & $842.786,84$ & Nhamundá & $354.434,00$ \\
\hline Apuí & $824.622,44$ & Autazes & $342.990,87$ \\
\hline Pauini & $738.395,28$ & Boa Vista do Ramos & $305.350,00$ \\
\hline Barreirinha & $684.000,17$ & Itacoatiara & $276.668,67$ \\
\hline Anamã & $648.297,86$ & São Paulo de Olivença & $269.469,42$ \\
\hline Ipixuna & $434.645,00$ & Maués & $235.608,16$ \\
\hline Nhamundá & $405.052,83$ & Humaitá & $215.645,46$ \\
\hline Coari & $402.652,01$ & Apuí & $132.940,56$ \\
\hline Guajará & $372.317,88$ & Manicoré & $125.888,32$ \\
\hline Tabatinga & $296.519,56$ & Presidente Figueiredo & $117.357,17$ \\
\hline Rio Preto da Eva & $204.172,00$ & Anori & $93.124,10$ \\
\hline Careiro & $201.526,80$ & Caapiranga & $89.952,16$ \\
\hline Maués & $146.285,47$ & Manaus & $32.631,17$ \\
\hline Humaitá & $124.644,00$ & Uarini & $25.212,00$ \\
\hline Jutaí & $108.592,83$ & Manaquiri & $23.540,56$ \\
\hline Maraã & $95.260,63$ & Jutaí & $22.119,00$ \\
\hline Alvarães & $90.607,97$ & Alvarães & $20.055,00$ \\
\hline Anori & $53.550,00$ & Amaturá & $16.161,00$ \\
\hline Caapiranga & $48.297,00$ & Nova Olinda do Norte & $2.094,00$ \\
\hline Outros quatro municípios & $157.204,17$ & Demais municípios & 0,00 \\
\hline Oculto & 25.956.142,64 & Oculto & $5.370 .919,73$ \\
\hline
\end{tabular}

Fonte: Elaborado pelos autores com base em Bacen (2013-2018).

Pelo valor total de créditos para a modalidade melhoramentos das explorações em agricultura e pecuária e pela quantidade de municípios contemplados, infere-se ser essa a modalidade de inovação mais recorrente no estado do Amazonas, no período. Cabe destacar ainda que alguns

8 ARAÚJO, A. B. F.; MAFRA, R. Z. Distribuição espacial e concentração do crédito rural no estado do Amazonas entre 20022018. Submetido. 
municípios localizados próximos ao arco do desmatamento (Apuí, Manicoré, Humaitá, Lábrea) direcionam mais créditos para atividade agrícola do que para a pecuária.

O resultado da análise das modalidades máquinas e equipamentos e ações de melhoramento das explorações não permite, contudo, comparações com o INCR, o qual aponta especialização em crédito rural para investimento na pecuária. Isso porque não foi aplicado o INCR para as duas modalidades de recursos para a inovação (máquinas e equipamentos e melhoramentos das explorações), e o INCR não está calculado por município, e sim para o estado do Amazonas.

Diferentemente dos recursos financeiros, o quantitativo de projetos submetidos para obtenção do crédito para aquisição de máquinas e equipamentos e para melhoramentos de explorações tem seguido esta dinâmica: em 2002, o quantitativo total era de 357 projetos contratados, sendo $67,86 \%$ desse total (228 projetos) destinados aos melhoramentos das explorações pecuárias. Em 2004, esse número salta para 4.233 projetos, sendo 72,7\% dos projetos (3.081) de melhoramentos das explorações agrícolas, conforme se observa na Figura 5.

Figura 5. Quantitativo dos projetos submetidos para obtenção de crédito rural para inovação na agropecuária amazonense entre 2002 e 2018.

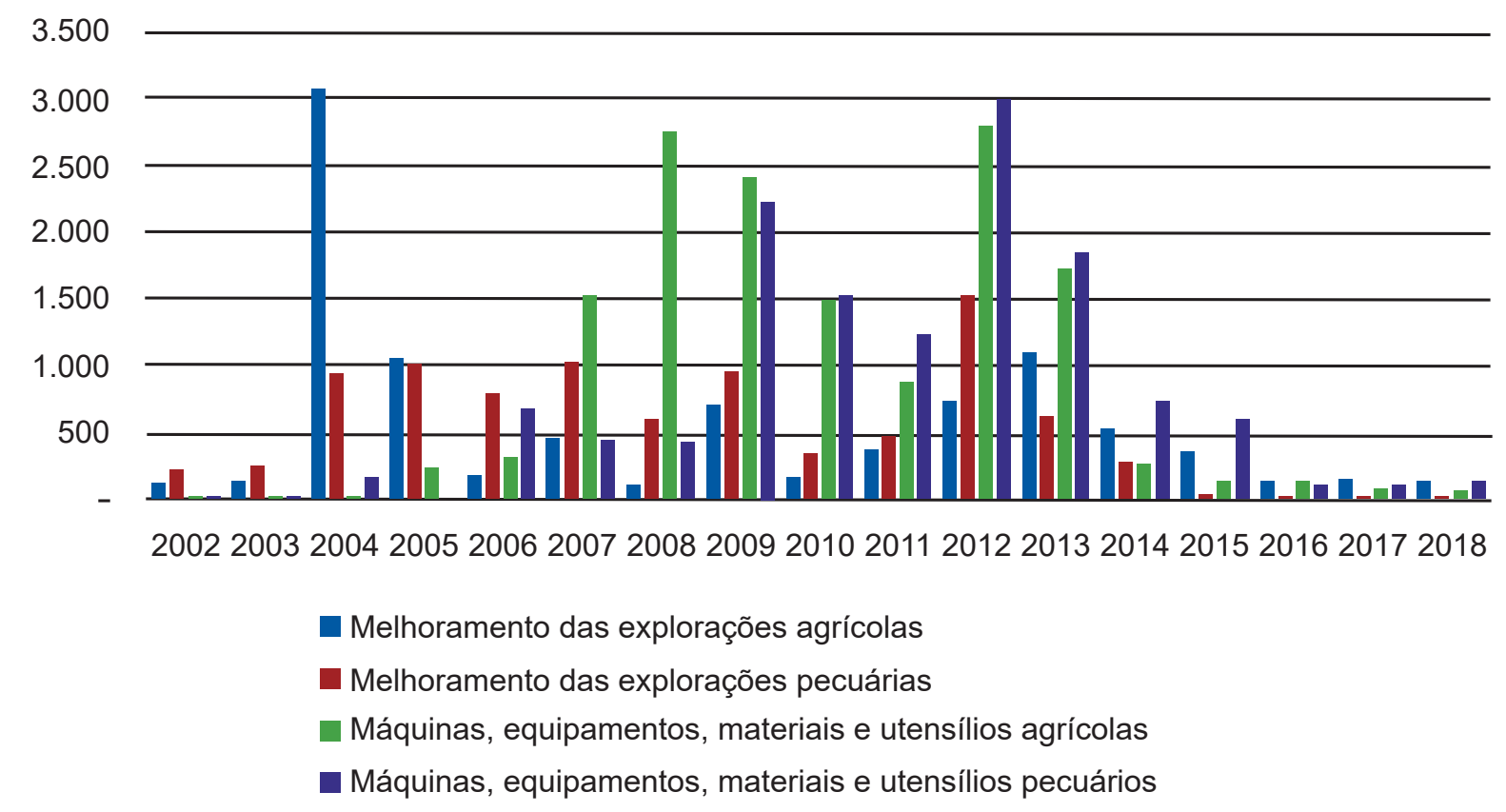

Fonte: Elaboração própria com base em BACEN (2002-2018).

Entre 2009 e 2013 observa-se que a prioridade foi dada para projetos de aquisição de máquinas e equipamentos para as duas atividades (agrícola e pecuária). A quantidade de recursos começou a declinar a partir de 2013, e isso está refletido na quantidade de projetos submetidos. Essa diminuição seguiu a tendência nacional (ARAÚJO; LI, 2018). 


\section{Conclusões e recomendações}

O aspecto negativo da especialização em crédito rural para investimento da pecuária é a aceleração do desmatamento no estado, oportunizado pelo melhoramento das tecnologias empregadas nessa atividade, como observado por Smeraldi e May (2008). Esse fenômeno tende a agravar, uma vez que o recém-lançado Projeto Inovação nas Cadeias Produtivas da Agropecuária para a Conservação Florestal na Amazônia Legal estimula atividades de agricultura extensiva.

Por outro lado, analisando a inovação de processo por meio das modalidades investimento, melhoramento das explorações e aquisição de máquinas e equipamentos, e considerando que a inovação em processo ocorre segundo o desempenho de técnicas, equipamentos e habilidades melhoradas (OECD/EUROSTAT, 2018), é possível afirmar a existência de recursos para a inovação nas duas atividades no estado do Amazonas: pecuária e agricultura, apesar da predominância de práticas de produção rudimentares de subsistência no estado, citadas por Petry et al. (2019).

Recomenda-se, porém, que estudos futuros identifiquem as particularidades do uso desses créditos, as quais não foram pormenorizadas neste estudo, tais como: se os investimentos estão sendo destinados para cruzamento de raças para melhoramento genético e reprodução, pastejo rotacionado, dieta do animal, utilização de ionóforos e outros, e resultados disso em inovação de produto. Do mesmo modo não foi identificada qual melhoria foi adotada na atividade agrícola (se fertilizantes, sementes ou insumos diversos). Tampouco identificou-se separadamente o programa que mais atende ao estado do Amazonas.

Desse modo, sugere-se ainda que novas pesquisas detalhem a dinâmica dos investimentos por programas agrícolas, possibilitando mais insights sobre a evolução dos investimentos e possíveis impactos sobre a inovação nos setores analisados. Importante também verificar o perfil fundiário dos estabelecimentos apoiados, assim como encontrar indicadores mais robustos sobre os impactos ambientais de alterações no nível e composição do crédito rural.

\section{Referências}

AMAZONAS. Lei $\mathbf{n}^{\mathbf{0}} \cdot \mathbf{3 . 0 9 5}$ de 17/11/2006. Dispõe sobre incentivos à inovação e à pesquisa científica e tecnológica no ambiente produtivo no âmbito do Estado do Amazonas, e dá outras providências. Manaus: Assembleia Legislativa do Estado do Amazonas, 2006. Disponível em: https://sapl.al.am.leg.br/media/ sapl/public/normajuridica/2006/7550/7550_texto_integral.pdf. Acesso em: 2 mar. 2020.

AMAZONAS. Secretaria de Planejamento, Desenvolvimento, Ciência, Tecnologia e Inovação SEPLANCTI. Anuário estatístico Amazonas 2017. Manaus, 2017. Disponível em: http://www.sedecti. am.gov.br/wp-content/uploads/2019/07/Anuario_Estatistico_do_Amazonas_ano_2017_.pdf. Acesso em: 15 jan. 2020.

ARAUJO, B. C.; LI, D. L. Crédito rural. In: NEGRI, J. A. D.; ARAUJO, B. C.; BACELETTE, R. (Org.). Financiamento do desenvolvimento do Brasil. Brasília, DF: IPEA, 2018. p. 225-258.

BANCO CENTRAL DO BRASIL - BACEN. Manual de crédito rural. Brasília, DF, 2018. Disponível em: https://www3.bcb.gov.br/mcr/completo. Acesso em: 28 fev. 2020. 
BANCO CENTRAL DO BRASIL - BACEN. Quantidade e valor dos contratos por municípios 2002, 2003, 2004, 2005, 2006, 2007, 2008, 2009, 2010, 2011, 2012, 2013, 2014, 2015, 2016, 2017, 2018. - contratações. Matriz de dados do crédito rural. Disponível em: https://www.bcb.gov.br. Acesso em: 22 set. 2019.

BANCO CENTRAL DO BRASIL - BACEN. Resolução $\mathbf{n}^{\mathbf{0}}$ 2998. Dispõe sobre o Programa de Desenvolvimento Sustentado da Floricultura (PRODEFLOR). Brasília, DF, 3 jul. 2002a. Disponível em: https://www.bcb.gov.br/pre/normativos/res/2002/pdf/res_2998_v2_1.pdf. Acesso em: 28 fev. 2020.

BANCO CENTRAL DO BRASIL - BACEN. Resolução No 2984. Dispõe sobre o Programa de Incentivo à Construção e Modernização de Unidades Armazenadoras em Propriedades Rurais (PROAZEM). Brasília, DF, 3 jul. 2002b. Disponível em: https://www.bcb.gov.br/pre/normativos/res/2002/pdf/res_2984_v2_L. pdf. Acesso em: 28 fev. 2020.

BANCO DO BRASIL. Moderfrota. Agronegócio - produtos e serviços. Brasília, DF, 2020a. Disponível em: https:/www.bb.com.br/pbb/pagina-inicial/agronegocios/agronegocio---produtos-e-servicos/credito/ investir-em-sua-atividade/moderfrota\#/. Acesso em: 20 jan. 2020.

BANCO DO BRASIL. PCA - Construção e ampliação de armazéns. Agronegócio - produtos e serviços. Brasília, DF, 2020b. Disponível em: https:/www.bb.com.br/pbb/pagina-inicial/agronegocios/agronegocio---produtos-e-servicos/credito/investir-em-sua-atividade/pca---construcao-e-ampliacao-de-armazens\#/. Acesso em: 20 jan. 2020.

BANCO NACIONAL DE DESENVOLVIMENTO ECONÔMICO E SOCIAL - BNDES. Moderinfra. Financiamentos. 2020a. Disponível em: https:/www.bndes.gov.br/wps/portal/site/home/financiamento/ produto/moderinfra. Acesso em: 20 jan. 2020.

BANCO NACIONAL DE DESENVOLVIMENTO ECONÔMICO E SOCIAL - BNDES. Inovagro. Financiamentos. 2020b. Disponível em: https:/www.bndes.gov.br/wps/portal/site/home/financiamento/ produto/inovagro. Acesso em: 20 jan. 2020.

BANCO NACIONAL DE DESENVOLVIMENTO ECONÔMICO E SOCIAL - BNDES. Moderfrota. Financiamentos. 2020c. Disponível em: https:/www.bndes.gov.br/wps/portal/site/home/financiamento/ produto/moderfrota. Acesso em: 20 jan. 2020.

BOZA, M. S.; VIEIRA, A. C. P.; ZILLI, J. C. Transferência de tecnologia para o campo: as inovações em implementos agrícolas na região do Mato Grosso. Revista da Universidade Vale do Rio Verde, v. 15, n. 1, p. 547-557, jan./jul. 2017.

BRASIL. Decreto $\mathbf{n}^{\mathbf{0}} \mathbf{8 . 2 6 9}$, de 25 de junho de 2014. Institui o Programa Nacional de Plataformas do Conhecimento e seu Comitê Gestor. Brasília, DF, 2014.

BRASIL. Lei $\mathbf{n}^{0}$ 4.829, de 5 de novembro de 1965. Institucionaliza o crédito rural. Brasília, DF: Presidência da República Casa Civil. Subchefia para Assuntos Jurídicos, 1965. Disponível em: http:// www.planalto.gov.br/ccivil_03/leis/L4829.htm. Acesso em: 23 jun. 2019.

BRASIL. Lei $\mathbf{n}^{\mathbf{0}}$ 11.196, de 21 de novembro de 2005. Dispõe sobre incentivos fiscais para a inovação tecnológica. Brasília, DF, 2005.

BRASIL. Projeto vai levar inovação nas cadeias produtivas da agropecuária para produtores da Amazônia Legal. Notícias. Brasília, DF, 2019. Disponível em: https://www.gov.br/pt-br/noticias/agricultura-e-pecuaria/2019/12/projeto-vai-levar-inovacao-nas-cadeias-produtivas-da-agropecuaria-para-produtores-da-amazonia-legal. Acesso em 30 jan. 2020. 
CARDOSO, J. L.; BITTENCOURT, G. A. A influência do crédito rural no Programa Inovagro - inovação na agropecuária. Brasília, DF: ENAP, 2019.

EUSÉBIO, G. S.; TONETO JUNIOR, R. Uma análise do acesso ao crédito rural para as unidades produtivas agropecuários do estado de São Paulo: um estudo a partir do Lupa. Revista Planejamento e Políticas Públicas, Brasília, DF, n. 38, p. 133-152, jan./jun. 2012.

FERNANDES, A. M. et al. Inovação na produção da carne bovina: uma revisão sistemática da literatura. In: SIMPÓSIO INTERNACIONAL DE INOVAÇÃO EM CADEIAS PRODUTIVAS DO AGRONEGÓCIO, 2., 2017, Caxias do Sul. Inovação e tecnologia no agronegócio como alternativa para a economia do Brasil [recurso eletrônico]. Caxias do Sul, RS: Educs, 2017. p. 330-343.

FRICKMANN, F. S. S.; VASCONCELLOS, A. G. V. Research and patente of phytotherapic and phytocosmetic products in the Brazilian Amazon. Journal of Technology Management \& Innovation, v. 6, n. 4, p. 136-150, 2011.

FUNARI, R. Queimadas e desmatamento colocam o Amazonas em emergência. Revista Exame, Caderno Brasil, ago. 2019. Disponível em: https:/exame.abril.com.br/brasil/queimadas-e-desmatamento-deixam-amazonas-em-emergencia/. Acesso: 2 mar. 2020.

FÜRSTENAU, V. O crédito rural no Brasil e seus efeitos sobre a agricultura gaúcha: 1965-84. Porto Alegre: FEE, 1988.

GRYZAGORIDIS, O. B.; FERREIRA FILHO, L. R. Impactos do crédito rural no Brasil. In: CONGRESSO DA SOCIEDADE BRASILEIRA DE ECONOMIA, ADMINISTRAÇÃO E SOCIOLOGIA RURAL, 46., 2008, Rio Branco. Amazônia, mudanças globais e agronegócios: o desenvolvimento em questão: anais. Brasília, DF: Sober; Rio Branco: UFAC, 2008.

LOPES, D.; LOWERY, S.; PEROBA, T. L. C. Crédito rural no Brasil: desafios e oportunidades para a promoção da agropecuária sustentável. Revista do BNDES 45, junho 2016. Disponível em: https://web. bndes.gov.br/bib/jspui/.Acesso em: 10 jan. 2020.

MAFRA, R. Z. et al. Distribuição espacial e concentração do crédito rural no estado do Amazonas. In: CONGRESSO DA SOCIEDADE BRASILEIRA DE ECONOMIA, ADMINISTRAÇÃO E SOCIOLOGIA RURAL, 57., 2019, Ilhéus. Agricultura, alimentação e desenvolvimento: anais eletrônicos. Ilhéus: SOBER, 2019.

MORA, M. A evolução do crédito no Brasil entre 2003 e 2010. Rio de Janeiro: IPEA, 2015. 59 p. (Texto para Discussão, 2022). Disponível em: http://repositorio.ipea.gov.br/bitstream/11058/3537/1/td2022.pdf. Acesso em: 22 set. 2019.

NASCIMENTO, M. N. C.; SANTOS, M. A. S.; ALMEIDA, R. H. C. Evolução e distribuição espacial das aplicações de crédito rural no estado do Amapá na primeira década do século 21. PRACS: Revista de Humanidades do Curso de Ciências Sociais da UNIFAP, n. 4, p. 79-94, dez. 2011.

OECD/EUROSTAT. Oslo Manual 2018: guidelines for collecting, reporting and using data on innovation. 4th Ed. Paris: OECD Publishing; Luxembourg: Eurostat, 2018. Disponível em: https://www.oecd-ilibrary.org/science-and-technology/the-measurement-of-scientific-technological-and-innovation-activities_24132764. Acesso em: 4 abr. 2020.

PETRY, J. F. et al. Inovação e difusão de tecnologia na agricultura de várzea na Amazônia. Revista de Administração Contemporânea, v. 23, n. 5, art. 2, p. 619-635, set./out. 2019.

PINHO, J. G. Investigando portais de governo eletrônico de estados do Brasil: muita tecnologia, pouca democracia. Revista de Administração Pública, v. 42, n. 3, p. 471-493, 2008. 
PIVOTO, D.; CARUSO, C. O.; NIERDELE, P. A. Schumpeter e a teoria do desenvolvimento econômico. In: NIERDELE, P. A.; RADOMSKY, G. F. W. Introdução às teorias do desenvolvimento. Porto Alegre: UFRGS, 2016.

PORTER, M. E. The contributions of industrial organization to strategic management. Academy of Management Review, v. 6, n. 4, p. 609-620, 1981.

PRODANOV, C. C.; FREITAS, E. C. Metodologia do trabalho científico [recurso eletrônico]: métodos e técnicas da pesquisa e do trabalho acadêmico. 2. ed. Novo Hamburgo: Feevale, 2013.

RAMOS, S. Y.; MARTHA JUNIOR, G. B. Evolução da política de crédito rural brasileira. Planaltina, DF: Embrapa, 2010.

RIVERO, S. et al. Pecuária e desmatamento: uma análise das principais causas diretas do desmatamento na Amazônia. Nova Economia, v. 19, n. 1, p. 41-66, 2009.

SALERNO, M. S. Políticas de inovação no Brasil: desafios de formulação, financiamento e implantação. In: COUTINHO, D. R.; FOSS, M. C.; MOUALLEM, P. S. B. (Org.). Inovação no Brasil: avanços e desafios jurídicos e institucionais. São Paulo: Bluncher, 2017. p. 79-96.

SCHUMPETER, J. A. Capitalismo, sociedade e democracia. Rio de Janeiro: Zahar, 1984.

SEIDLER, E. P.; FRITZ FILHO, L. F. A evolução da agricultura e o impacto gerado pelos processos de inovação: um estudo de caso no município de Coxilha - RS. Economia e Desenvolvimento, v. 28, n. 1, p. 388-409, jan./jun. 2016.

SMERALDI, R.; MAY, P. O Reino do Gado: uma nova fase: uma nova fase de pecuarização da Amazônia. São Paulo: Amigos da Terra - Amazônia Brasileira, 2008. 40 p.

SPOLADOR, H. F. S. Reflexões sobre a experiência brasileira de financiamento agrícola. 2002.93 f. Dissertação (Mestrado em Economia Aplicada) - Universidade de São Paulo, Piracicaba, 2002.

TOLEDO NETO, E. R.; COUTO JUNIOR, A. F. Índice Normalizado de Agricultura e Pecuária (INAP) para caracterização da dinâmica de concessão de crédito rural em Goiás. In: SIMPÓSIO BRASILEIRO DE SENSORIAMENTO REMOTO, 15., 2011, Curitiba. Anais... São José dos Campos: INPE, 2011. p. 176-183.

VAN DER VEEN, M. Agricultural innovation: invention and adoption or change and adaptation? World Archaeology, v. 42, n. 1, p. 1-12, 2010. 
